\title{
Arnaud Tripet, Écrivez-moi de Rome... Le mythe romain au fil du temps
}

Fatima Pilone

\section{Q OpenEdition \\ 1 Journals}

\section{Edizione digitale}

URL: https://journals.openedition.org/studifrancesi/46449

DOI: 10.4000/studifrancesi.46449

ISSN: 2421-5856

\section{Editore}

Rosenberg \& Sellier

\section{Edizione cartacea}

Data di pubblicazione: 1 octobre 2007

Paginazione: 491-492

ISSN: 0039-2944

\section{Notizia bibliografica digitale}

Fatima Pilone, «Arnaud Tripet, Écrivez-moi de Rome... Le mythe romain au fil du temps», Studi Francesi

[Online], 152 (LI | II) | 2007, online dal 30 novembre 2015, consultato il 24 novembre 2021. URL: http:// journals.openedition.org/studifrancesi/46449; DOI: https://doi.org/10.4000/studifrancesi.46449

Questo documento è stato generato automaticamente il 24 novembre 2021.

\section{(c) (i) (9)}

Studi Francesi è distribuita con Licenza Creative Commons Attribuzione - Non commerciale - Non opere derivate 4.0 Internazionale. 


\title{
Arnaud Tripet, Écrivez-moi de Rome... Le mythe romain au fil du temps
}

\author{
Fatima Pilone
}

\section{NOTIZIA}

ARNAUD TRIPET, Écrivez-moi de Rome... Le mythe romain au fil du temps, Paris, Honoré Champion, 2006, pp. 540.

1 Arnaud Tripet ha insegnato letteratura francese e italiana all'Università di Chicago e di Losanna e si è interessato a lungo di una cultura millenaria come quella romana. Il suo nuovo libro, Écrivez-moi de Rome, è il risultato di questo fascino che l'autore ha sempre subito da parte di una tradizione antichissima e che egli analizza, soffermandosi proprio su come essa è stata ed è percepita dagli esponenti del mondo artistico e, soprattutto, letterario.

2 Sono infatti moltissimi coloro che, prima di Tripet, hanno nutrito un grande interesse nei confronti di Roma, dagli antichi ai moderni, dai poeti ai viaggiatori, dai romanzieri agli artisti.

3 Il volume è suddiviso in otto capitoli («Rome par elle-même»; «Une autre Rome»; «Tourments lyriques»; «Rome tragique»; «L'air de Rome»; «Rome, atelier du moi»; «Réalité romaine»; «Méfiance et catharsis»): il lettore è accompagnato in una passeggiata tra la Roma mitica e quella reale, in una città scoperta attraverso i secoli che, in letteratura, hanno parlato di lei. Si rivela una città segnata dal prestigio, vista come esemplare, al punto da essere proposta ai bambini sin dai primi studi d'infanzia, con quello che Tripet definisce le lait de Rome, come avviene, ad esempio, per autori come Petrarca o Montaigne, educati attraverso i racconti sulla città. E ancora Roma, vista come il centro dell'Impero e, quindi, di una storia densa di significati, ma che diviene poi il centro del messaggio cristiano.

4 Molti scrittori hanno raccontato la città, l'Impero, la sua immensità, dando vita a un'idea di grandeur che è sopravvissuta allo scorrere del tempo. Vengono poi le 
descrizioni più realistiche, come nel caso di du Bellay, e si arriva alla Roma dei Papi, della politica europea della Chiesa, delle ambizioni e della falsità.

5 La letteratura ha a lungo fornito un'immagine di Roma come simbolo della virtus e della gloria, dove a volte però si può aprire uno spiraglio di comicità, come nel caso dei servitori shakespeariani. Tripet analizza le tragedie di Corneille e di Racine, dove la città romana ha un'importanza centrale. Si sofferma poi su quei testi che si mostrano come vere e proprie passeggiate, occasione per i vari autori di fornire anche brevi cenni storici.

6 Infine, Roma è anche fonte di ispirazione, desiderio di apprendere, ad esempio per Goethe. È quello che Tripet definisce "laboratorio dell'io", dove la città è alla base di un'impresa in cui l'autore parla di sé stesso, come nel caso di Chateaubriand o di Stendhal.

7 Anche nel xx secolo Roma non ha smesso di far scrivere. Si tratta però, per la maggior parte, di testi molto diversi rispetto a quelli precedenti, spesso brevi, destinati a giornali o riviste, dove si coglie meno quel senso di grandezza sopra descritto, a favore di un taglio più realistico, meno mitico.

Il volume si conclude con una bibliografia selettiva e l'indice dei nomi propri. 